\title{
Research and Survey on Development of Qingdao Amateur Tennis Matches
}

\author{
$\mathrm{Li} \mathrm{Liu}^{1}$ \\ ${ }^{1}$ Department of Physical Education, Qingdao University of Science and Technology, Qingdao, Shandong, China \\ Correspondence: Li Liu, Department of Physical Education, Qingdao University of Science and Technology, \\ Qingdao, Shandong, China. E-mail: 13969851549@163.com
}

Received: July 21, 2014 Accepted: July 28, 2014 Online Published: July 28, 2014

doi:10.5539/ass.v10n16p196 URL: http://dx.doi.org/10.5539/ass.v10n16p196

\begin{abstract}
This essay takes amateur athletes who are between 20 to 60 years old and took part in amateur tennis matches of recent years as targets. It has profound significance to analyze the styles, scales and behaviors of the matches because it can provide reference to advocate healthy modern lifestyle and nationwide fitness program. This essay employs documentation method, questionnaire method, method of comparative analysis, mathematical statistics method and experts interview to do the research. The study is based on the basic information, the development and effects of Qingdao amateur tennis matches. The survey demonstrates that there have been some accomplishments for Qingdao amateur tennis matches. Participants of amateur tennis matches are of different ages and occupations. The organization and equipment as well as the playing ground are not so good and need to be improved.
\end{abstract}

Keywords: Qingdao, amateur, tennis match, development

\section{Introduction}

Tennis is a beautiful and fierce sport. The origin and development of tennis can be summarized in four sentences: bred in France, born in England, spread and reach a peak in US, now prevalent all over the world.

Domestic tennis has developed a lot in recent years. The average level of amateur tennis players are constantly improving. More matches are organized towards amateur players. However, as amateurish match, the host should think about the following questions: what is the purpose of the match, how much entry fee for participants, how to check qualification, how to arrange match schedule, what match system is fairest, how to group, how to award participants and what does the sponsor get in return for sponsoring. It has been well developed for Qingdao amateur tennis matches in recent years. It has been 30 years since 1970s when the amateur tennis match is first held. More matches are held and more players participate year by year. So far, there have been some matches that are held regularly as well as other events in different levels. Amateur tennis players from all levels of society take part in the match and enjoy it very much. To some extent, the amateur tennis matches in Qingdao are better than other areas nationwide. Some problems also appear along with more matches with different levels. According to the analysis towards the amateur tennis match in Qingdao in recent years and the basic information (scale, density, level, amount), as well as the effects that the amateur matches have on amateur players' level, it can provide objective basis to train new players. It is also quite useful to conduct Qingdao amateur tennis match, ensure the do's and don'ts as well as major directions of organization and make regulations that are in accordance with actual Qingdao amateur tennis matches.

\section{Research Target and Method}

\subsection{Research Target}

The study is based on amateur tennis match participants who are between 20 and 60 years old and who took part in Qingdao Sports Lottery Cup amateur tennis match recent years.

\subsection{Research Method}

\subsubsection{Documentation}

Having checked more than 20 documentations about amateur tennis match within recent 10 years; Collect data about amateur matches held by Qingdao Tennis Association in recent 5 years and data of "China Statistical 
Yearbook for Regional Economy" published by Comprehensive Department of National Bureau of Statistics.

\subsubsection{Questionnaire}

Set questions according to needs. Give out 50 questionnaires in all and 50 returns. The completion rate is $100 \%$. There are 49 effective questionnaires among all 50 and the effective rate is $98 \%$.

\subsubsection{Comparative Analysis}

The essay made a horizontal comparison between developments of amateur tennis matches in Qingdao areas and other provinces in China to find the differences and shortages. And also there is a vertical comparison towards "Bandao Cup" participants of 2008 and 2009 which will show the development trends.

\section{Results and Analysis}

\subsection{Status of Qingdao Amateur Tennis Match}

\subsubsection{Level of Matches}

With the establishment and developments of level 123 system for China tennis match, Qingdao also adopts this system. The 2012 and 2013 "Bandao Cup" matches studied in this essay falls into level 3 and is a provincial amateur tennis match with a small scale.

\subsubsection{Playing Field of Qingdao Amateur Tennis Match}

Playing filed is the necessary part to play tennis and hold a match. The amount of playing field in Qingdao is the basis to better develop amateur tennis match and also the constraint for the match developments. The playing fields for amateur tennis match in Qingdao are characterized by the followings: 1. Area distribution is relatively single. Most matches are held in urban area and few in counties; 2 . The playing field is not well distributed. The number of playing fields (college playing field included) in urban area reaches 40 while there is few or one for other areas; 3.Medium class faculties occupy the most. Most of the playing fields for amateur tennis matches in Qingdao are plastic outdoors. Only eighth finals and quarter finals can be held indoors or with standard playing field. And few matches will be held with college courts; 4. Large scale playing field (e.g. four playing fields connected together) is few and single or double playing fields make up the majority. Besides, the construction of playing field depends on government, real estate developer and school's infrastructure. On one hand, the insufficient playing fields restrict the development of amateur tennis match; on the other hand, current playing fields are not fully used due to traffic inconvenience. In reverse, there factors restrict the construction of tennis playing fields.

\subsubsection{Time to Hold Amateur Tennis Match in Qingdao}

Time to hold the tennis match is the important factor to determine the excitement of players. International matches are usually held between 5 to 9 PM in the evening. Domestic matches are held in the morning or afternoon from May to October due to some restrictions (playing field, weather, resources distribution). The "Bandao Cup" matches are held from the middle of June to early of July in accordance with the demand of domestic matches. The time is 8.30 --- 11.30 AM and 1.30-5.00 PM.

\subsubsection{Organizer of Qingdao Amateur Tennis Match}

There are relatively less amateur tennis matches in Qingdao for now but showing a growing trend. Qingdao hosted the "Xuehua Cup", the national amateur tennis competition. And on May Day and National Day of each year, Qingdao will hold some amateur tennis matches with small scale. In addition, there are some intercity dual meets among Qingdao, Yantai and Jinan. However, it is obvious that the plan and scheme are not so good. The main task for the organizer is to organize the match elaborately, differentiate the levels, and set up elimination match and main draw match which can make players in different levels enjoy the match. The study shows that the match is over only with several rounds for "Bandao Cup". This will harm the enthusiasm of players to participate matches and even the enthusiasm to play tennis in the future. On the other hand, there is not much combination with enterprises. Tennis is a sport of fashion and elegance. The participants are with high social status, income and consumption ability. Amateur tennis match can not only bring fun and competition to participants but also social benefits to sponsors if it is well promoted. In fact, some enterprises and public institutions have realized it. Therefore, the organizers of tennis match should try to get sponsorship from them. The good promotion and organization towards matches will bring social benefits to sponsors and form the virtuous cycle for amateur tennis match. In the meanwhile, the tennis can get well improved via matches. 


\subsection{Basic Information about Participants of Qingdao Amateur Tennis Match}

\subsubsection{Quantity Feature}

It shows from table 1 that the number of male players is more than that of female layers. Players of 20 to 40 years old make up $71.32 \%$ of all players and 40 to 60 years old only share $27.68 \%$. This shows tennis is a sport played mostly by young people. Education level also has effect on tennis. Players with or over a degree of technical secondary school makes up the great majority (97.32\%) among the players in the study.

Table 1. Age, gender and education level of amateur tennis match in Qingdao (\%)

\begin{tabular}{lllllllll}
\hline Gender & Age & \multicolumn{2}{l}{ Educational } & & & & \\
\hline Male & Female & $20-40$ & $40-60$ & Graduate & Undergraduate & College included) & (Junior & Technical \\
Secondary School & Primary \\
17 & 8 & 20 & 6 & 2 & 13 & 8 & 1 \\
68.54 & 31.46 & 71.32 & 27.68 & 5.32 & 59.27 & 32.76 & 2.68 \\
\hline
\end{tabular}

\subsubsection{Areal Distribution}

As a sport that requires a high level of technique and playing field as well as cost compared with other sports, most amateur tennis players come from urban areas where the economy is well developed. This also shows that the development of tennis is related to the development of local area and the location.

Table 2. Area distribution of amateur tennis match in Qingdao

\begin{tabular}{llllll}
\hline & Shinan District & Laoshan District & Sifang District & Shibei District & Chengyang District \\
\hline Amount & 20 & 9 & 9 & 8 & 4 \\
Percentage & $20.69 \%$ & $5.16 \%$ & $2.32 \%$ & $2.22 \%$ & $1.77 \%$ \\
\hline
\end{tabular}

\subsubsection{Occupation}

It shows from table 3 that most players of Qingdao amateur tennis players are teachers and students from colleges, civil servant and enterprise employee make up another part and the rest are free-lances. Colleges and universities have advantages in environment, playing field and faculty so they take the leading position in many sports including tennis. The number and level of participants are also better. Another reason is that the playing field is free to teachers and students and the cost is lower compared with other players.

Table 3. Occupations of amateur tennis match in Qingdao

\begin{tabular}{lll}
\hline Occupation & Amount & Percentage (\%) \\
\hline Intellectual (Mainly Undergraduates) & 26 & 55.64 \\
Civil Servant & 12 & 22.36 \\
Enterprise Employee & 10 & 20.17 \\
Freelance & 2 & 1.83 \\
\hline
\end{tabular}

\subsection{Analysis of Reasons that Affects the Developments of Qingdao Amateur Tennis Matches}

\subsubsection{Matches Information}

From the study, it can be concluded that the main factors influence the development of amateur tennis matches in Qingdao are playing fields, sponsor, economy and spare time. For playing fields, 60.64 of the interviewee think the amount is too less, which shows there is a direct relationship between developments of tennis match and playing filed. For sponsor, $60.73 \%$ think the sponsors are common. And a lot of people think the level of judges is too weak. So the level of judges has influence towards the developments of tennis match. Tennis is a sport that need much cost according to the research towards tennis players.

It shows from table 4 that personal financial condition will have effects on which sport they choose as the lifetime sport. Another factor that influences the tennis match development is spare time. Nearly half people think the time is limited and it is unfavorable for tennis match developments. 
Table 4. Main factors influencing amateur tennis match (\%)

\begin{tabular}{llll}
\hline Factor & Percentage $(\%)$ & & \\
& Positive & Average & Negative \\
\hline Playing field & 7.16 & 32.20 & 60.64 \\
Sponsorship & 17.39 & 60.73 & 21.88 \\
Organization & 41.21 & 50.63 & 8.16 \\
Schedule & 10.26 & 40.23 & 49.5 \\
\hline
\end{tabular}

\subsubsection{Participants}

After many years' developments, the tennis technique has got the following features: fast speed to hit the ball, much physical strength, less miss and the variety of placement and routes. Comparing the "Bandao Cup" amateur tennis match in 2008 and 2009 with matches of Beijing and Shanghai, there are still shortages in the number of participants. There are 100-150 participants. Players in Qingdao fall behind in technique which mainly demonstrates in: motion is not standard, technique is single, too many fault; in tactics, the offensive is weak, the target is unclear, does not adopt corresponding tactics according to opponent's technique feature and more defensive than offensive. Few players are net rushers. Few players score by volleying the ball or with smash. The only several ones are done due to the opponent's movements. Most players do not adopt smash technique even there is a good chance. And they use forehand drive after the ball falls on ground. This shows players lack the sense of offensive and the technique is low and single.

\section{Conclusions and Suggestions}

\subsection{Conclusions}

Tennis matches attracts many sports enthusiast with the special value and charm. Most participants vary in ages, occupations and other aspects. The main motivations to take part in the match are building up body, cultivate taste and show them. It is the precondition to improve the level of Qingdao amateur tennis match that strengthening the construction and input of equipment and judges. There are not so much tennis matches in Qingdao currently and more work need to be done to let more tennis players know and take part in the match as well as communicating with each other.

Tennis can cultivate a team cooperation spirit. Tennis match depends much on team work. There should be tacit cooperation between coach and team members, team competition and teammates and partners of doubles. And the tacit derives from the team work spirit of every player.

\subsection{Suggestions}

According to the interview towards some tennis club, it shows many coaches and teachers did not receive systematic training in professional technique and theory while they teach and train players on the basis of their own understanding and experiences. This is quite unfavorable for players, especially youth players to improve technique and static level in a scientific and systematic way. It will cause irretrievable loss for the development of players and brings hidden troubles for players to train and step into a higher level.

The cost to build and maintain tennis playing field is high. So it is necessary to build walls and simple playing field to practice. For areas that the sports funds are limited, it is a good way to seek support from enterprises and people who are enthusiastic about tennis and charge in a reasonable rate towards the usage of playing fields. This will not only get some funds for playing fields but also deepening the understanding to sport events and finally they will change from passive to active and get into the habit of lifetime exercise.

It is quite helpful to get support from administrative department and leaders. Then strengthen the unified management towards amateur tennis match in Qingdao and establish a set of management and organization system to promote the value and meanings of tennis. Finally advance the developments of amateur tennis matches in Qingdao.

The change of perception and ideas are necessary and guide people to consume on tennis relevant industry. There are many social values that can be derived from tennis. So the industrialization and socialization of tennis in Qingdao will be quite helpful to promote the development of tennis and in return consumers will be motivated to spend on tennis. The development of amateur tennis matches will hence get more chance. There will be a virtuous circle come into being. 


\subsubsection{Continue to Deepen the Reform of the System}

System reform has been high on agenda for government reform. The management way for government needs to be changed from direct management to indirect management as well as from micro control to macro control. The single administrative order should not be the only way for government to manage the society and more ways like law, regulations and economic means needs to be taken into consideration. By the above changes, a well-organized, competitive and effective operating system for tennis will be established. Set up a system that consists of policy guidance, law guidance and supervision and straighten out the relationship between management department and association as well as other tennis organizations. In the process of exploring reforms and developments, both positive and negative experience should be gathered to advance the reform and development of tennis industry management.

\subsubsection{Continue to Strengthen and Improve Professional Tennis Club System}

For those professional tennis clubs that are in tennis market, they should be business entities of clear ownership, well defined power and responsibility, independent management, sole responsibility for their own profit and losses and scientific management. Currently, the professional clubs in Qingdao are different with the actual professional club technically. In order to become the professional clubs that are worthy of the name, property right reform and standard management are necessary.

\subsubsection{Improve the Competitiveness of Tennis Matches}

Competitiveness is the symbol of tennis sport which is a special kind of commodity. The relationship of practice and match needs to be well dealt with and the competition system, training system also needs further reform. It is much better to build a brand, form a nice image and tennis star. Focus on cultivating famous tennis players who can attract more people to pay attention to tennis sport and play tennis. Strengthen international and domestic communication and cooperation. Learn the advanced training method and experience from them and use by ourselves.

\subsubsection{Do Further Research on Tennis Market}

They are weak fields about the tennis industry, tennis market and the relationship between tennis and economy. It is suggested that General Administration of Sport and Tennis Management Center strengthen the reform guidance and scientific input to provide theoretical basis for the developments of Qingdao tennis market.

\subsubsection{Promote the Development of Tennis from Citywide Level}

The departments, schools and organizations should increase input to tennis and create conditions to make more people interested in tennis. Tennis is a popular sport that can be played by all levels of people. Try to make the above measures taken and we believe that tennis will be developed in a rapid way in Qingdao.

\section{References}

Cen, R. J. (2008). Study on Marketing of Tennis Commercial Club. Journal of Guangxi University (Philosophy and Social Science).

Han, X. P., \& Yan, J. M. (2007). Current Situation and Development Advices on China Public Tennis Sport. Journal of Physical Education Institute of Shanxi Normal University.

Ji, D. S. (2006). Analysis on Health and Sports Participancy of China Intellectual, Journal of Capital Institute of Physical Education. Journal of Shandong Institute of Physical Education and Sports.

Qi, Y. L. (2009). Study on Current Situation of Mini Tennis Development towards Anhui Youth. Journal of Anhui Sports Science.

\section{Copyrights}

Copyright for this article is retained by the author(s), with first publication rights granted to the journal.

This is an open-access article distributed under the terms and conditions of the Creative Commons Attribution license (http://creativecommons.org/licenses/by/3.0/). 